\title{
Primitive Internal Hernia in Adult: A Report on 6 Cases Narjis $Y^{*}$ and Finech $B$ \\ Department of general Surgery, University Hospital Mohamed VI, Cadi Ayyad University, Morocco
}

\begin{abstract}
Introduction: Primitive Internal hernias in adult are rare. There are many types of these hernias. We report the experience of our department in the management of this pathology.

Patients and methods: it was a retrospective study reporting six cases (three males, three females) of primitive internal hernias, with a mean age of 31.75 years.

Results: Acute intestinal obstruction was present in 4 cases. The interval between the development of symptoms and hospitalization ranged from 24 to 72 hours (mean: 52 hours). We found two paraduodenal hernias, two primitive adhesions and one case of each of the other types: primitive transmesocolic and transomental herniations. CT scan helped to diagnosis in four cases. Resection of small bowel was done in two patients. We deplored no death but two cases of wound infection. The length of hospital stay was 6.4 days (3-10 days).
\end{abstract}

Conclusion: our series confirmed the young age of this pathology with no sex prediction. It also confirmed the preponderant place of CT scan in the management of these patients.

Keywords: Internal hernia; Primitive; CT scan; Laparoscopy

\section{Introduction}

Internal hernia is defined as the protrusion of an abdominal organ through a peritoneal or mesenteric aperture. It is a rare cause of small bowel obstruction. The incidence of these hernias is estimated at between 0,2 and $2 \%$ of abdominal hernias, and $0.2 \%$ to $0.9 \%$ of autopsies [1,2]. It can be primitive or secondary to an abdominal intervention. Internal hernias are classified based on the location of the potential defect. The aim of our study is to report 6 cases of primitive internal hernia, representing different anatomical types.

\section{Patients and Methods}

Six patients of a mean age of 31,7 years (range 24-75) were admitted to our department of general surgery, at Mohamed VI university hospital of Marrakech (Morocco), on emergency during a period of six years (from 2006 to 2011). We reported 3 males and 3 females. All patients denied any surgery or intra-abdominal inflammatory process.

We reviewed the patient's records, imaging modalities and operative findings of these cases.

All patients were operated.

\section{Results}

All patients consulted on emergency. Table 1 shows the presenting symptoms of our patients. Acute intestinal obstruction was found in 4 cases $(66 \%)$. Other abdominal symptoms were found: abdominal pain $(n=6)$, nausea $(n=2)$, vomiting $(n=5)$. The interval between the beginning of symptoms and hospitalization ranged from 24 to 72 hours (mean: 52 hours). The physical exam revealed abdominal distention in 4 patients (66\%), abdominal tenderness in 2 patients (33\%), and fever and peritonitis in three patients (50\%). One patient presented a septic shock.

Abdominal X-ray showed air fluid levels in four patients (66\%). Ultra sonography examination showed peritoneal fluid in also four patients. CT scan was done in four patients on emergency.

It suggested non specific internal herniation in two patients. In the other two patients, it suggested a specific internal herniation: a paraduodenal hernia in a case and a gastric herniation in the other case (Figure 1).

All patients went under surgery by laparotomy. The surgical exploration found:

$>$ Left paraduodenal hernia: 2 cases

$>$ Primitive adhesion between sigmoid and small bowel: 1 case (Figure 2)

$>$ Transomental hernia: 1 case.

$>$ Right transmesocolic hernia: 1 case

$>$ Primitive Omento-diaphragmatic adhesion, strangulating stomach: 1 case (Figure 3)

$>$ The surgical treatment for those different types of hernias is explained in Table 2.

$>$ Small bowel resection was done in two patients.

We had no death in our six patients. Two cases of wound infection were reported classified Grade I in the Clavien-Dindo classification of surgical complications. These patients were treated by antibiotics

\begin{tabular}{|c|c|}
\hline Symptoms at presentation & Number of patients (\%) \\
\hline $\begin{array}{c}\text { Acute abdominal } \\
\text { obstruction }\end{array}$ & $4(66 \%)$ \\
\hline Abdominal pain & $6(100 \%)$ \\
\hline Vomiting & $5(83 \%)$ \\
\hline Nausea & $2(33 \%)$ \\
\hline Peritonitis & $3(50 \%)$ \\
\hline shock & $1(16 \%)$ \\
\hline leukocytosis & $3(50 \%)$ \\
\hline
\end{tabular}

Table 1: Clinical symptoms at presentations of the six patients.

*Corresponding author: Youssef Narjis, Assistant Professor, Faculty of medicine Cadi Ayyad University, Marrakech, Morocco, Tel: 00212667045433; E-mail: y.narjis@ yahoo.fr

Received May 04, 2015; Accepted June 16, 2015; Published June 23, 2015

Citation: Narjis Y, Finech B (2015) Primitive Internal Hernia in Adult: A Report on 6 Cases. Surgery Curr Res 5: 235. doi:10.4172/2161-1076.1000235

Copyright: ( $\odot 2015$ Narjis Y, et al. This is an open-access article distributed under the terms of the Creative Commons Attribution License, which permits unrestricted use, distribution, and reproduction in any medium, provided the original author and source are credited. 


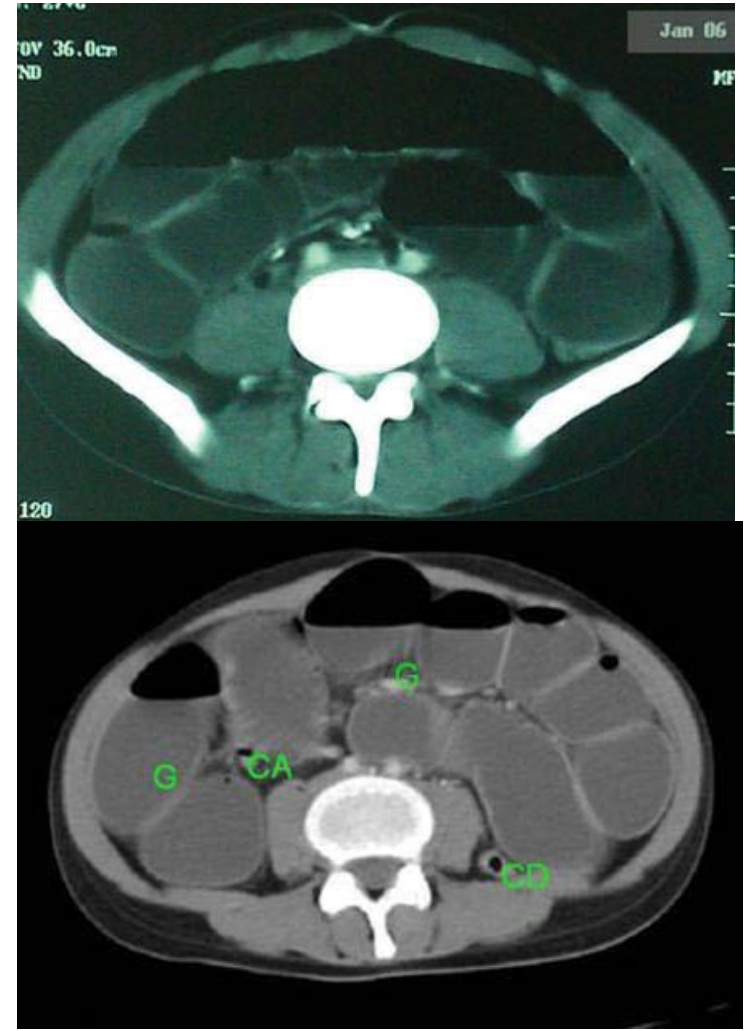

Figure 1: CT scan of our patients showing the internal herniations: $A$ ) Computed tomography (CT) scans showing a distension of the bowel in a patient with a primitive adhesion between sigmoid and small bowel. B) Computed tomography (CT) scan showing a non specific internal herniation, and at surgical exploration right transmesocolic herniation.

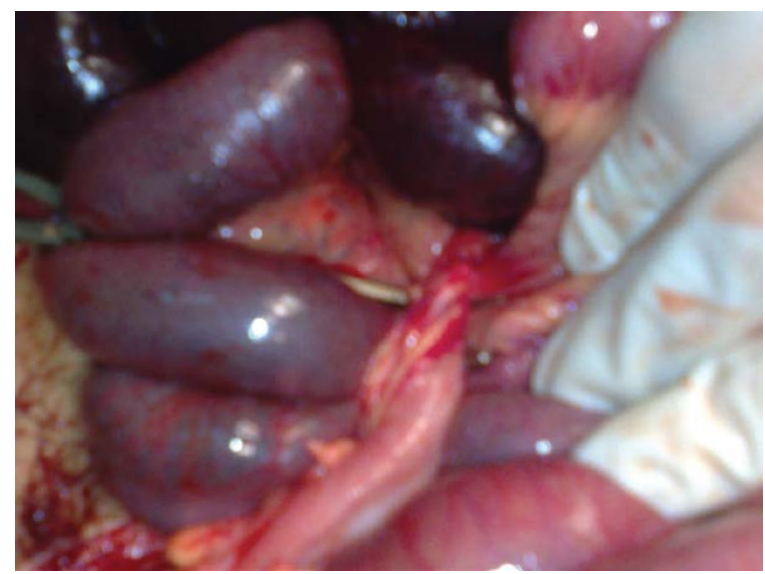

Figure 2: per operative view of the primitive adhesion (1) between small bowel and sigmoid colon, with necrotic small bowel (2).

(Ciprofloxacin $500 \mathrm{mg} /$ two times a day for 5 days) and had local treatment. The length of hospital stay was 6.4 days ( $3-10$ days).

\section{Discussion}

An internal abdominal herniation is the protrusion of an abdominal organ through a normal or abnormal mesenteric or peritoneal

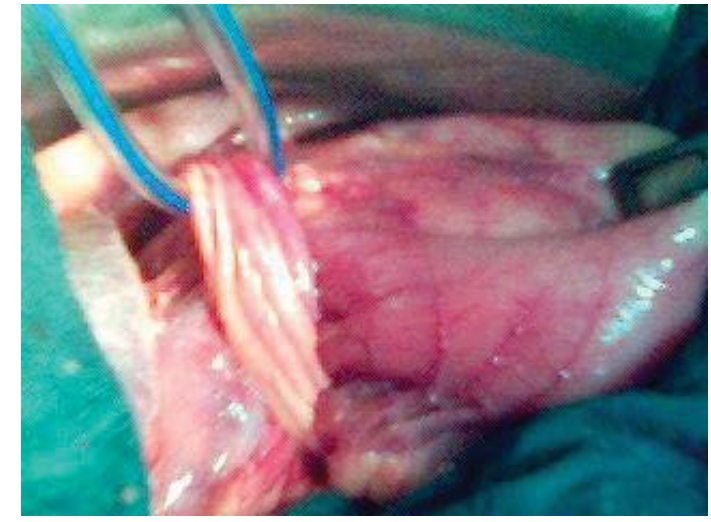

Figure 3: Primitive Omento-diaphragmatic adhesion (1) strangulating stomach (2).

\begin{tabular}{|c|c|c|}
\hline Type of primitive hernia & Number of cases & treatment \\
\hline Left para duodenal hernia & 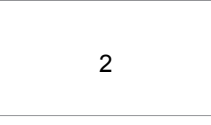 & $\begin{array}{l}\text { Closure of the } \\
\text { defect,Small bowel } \\
\text { resection: one } \\
\text { cases }\end{array}$ \\
\hline Trans omental hernia & 1 & $\begin{array}{l}\text { Reduction of small } \\
\text { bowel,omental resection }\end{array}$ \\
\hline Transmesocolic hernia & 1 & $\begin{array}{l}\text { Reduction of small } \\
\text { bowel,Closure of the } \\
\text { defect,coecopexy }\end{array}$ \\
\hline $\begin{array}{c}\text { Primitive adhesion } \\
\text { betweensigmoid and small } \\
\text { bowel }\end{array}$ & 1 & $\begin{array}{l}\text { Small bowel } \\
\text { resection, Resection of the } \\
\text { adhesion }\end{array}$ \\
\hline $\begin{array}{l}\text { Omento diaphragmatic } \\
\text { adhesion strangulating } \\
\text { stomach }\end{array}$ & 1 & Resection of the adhesion \\
\hline
\end{tabular}

Table 2: Surgical findings and specific surgical treatment of each type.

aperture. Internal abdominal herniations can be either acquired through a trauma or surgical procedure (iatrogenic internal abdominal herniations) or constitutional, related to congenital peritoneal defects $[2,3]$. In the broad category of internal hernias are several main types, as traditionally described by Meyers [4], based on location.

In literature, there are many types of primitive internal types, as traditionally described by Meyers [4], based on location.

Specifically, using historical data, these consist of paraduodenal (53\%), pericecal (13\%), foramen of Winslow (8\%), transmesenteric and transmesocolic (8\%), intersigmoid (6\%), and retroanastomotic (5\%) (Figure 4).

In literature, series reporting primitive internal hernias (PIH) are rare. PIH have no sex predilection as in our series (3 males, 3 females) [4]. The patients in our series were very young (mean age: 31.7 years) comparing to other series: Gullino and al (45 years), Armstrong and al (71 years) and Akyildiz and al (50 years) $[1,5,6]$.

There is no specific symptom for PIH. Abdominal pain and acute small bowel obstruction are the most common presentation as in our cases. Other symptoms have been reported as intermittent bowel obstruction, peritonitis (in three of our cases), fever, nausea, vomiting and sepsis [2]. Symptom severity relates to the duration and reducibility of the hernia and the presence or absence of incarceration and strangulation [6]. 


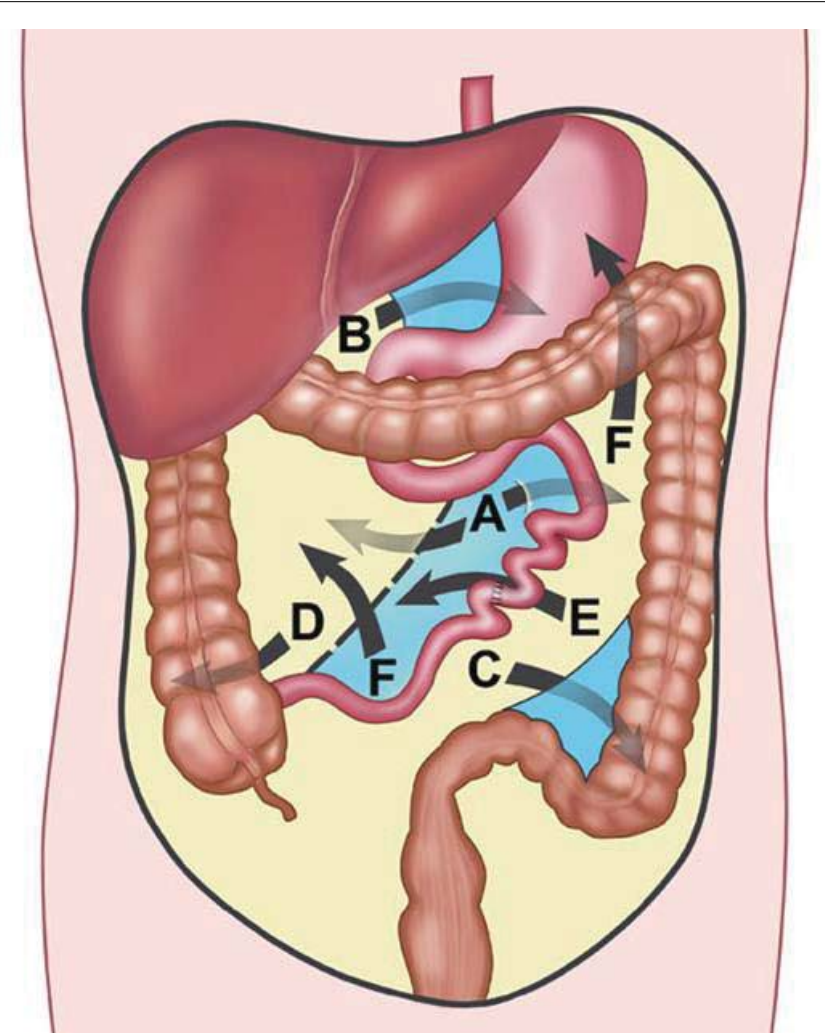

Figure 4: Diagrammatic illustration shows various types of internal hernias:

( $\alpha$ ) Paraduodenal, (b) foramen of Winslow, (c) Intersigmoid, (d) Pericecal, (e) Transmesenteric, (f) Retroanastomotic.

Imaging studies often play an important role in the diagnosis of internal hernias because of the non specificity of clinical signs. CT is the first-line imaging technique in these patients because of its availability, speed, and multiplanar reformatting capabilities. CT could show the hernia sac and its anatomic relationship to the surrounding organs and vasculature. It can also find mesenteric vessel abnormalities, with engorgement, crowding, twisting, and stretching of these vessels commonly found and providing an important clue to the underlying diagnosis [7-9]. In our series, it showed no specific signs suggesting internal hernia in two cases, but in the other two cases, it confirmed the exact type of the hernia.

The treatment of these herniations depends on the surgical findings. In the absence of necrosis, it consists of a reduction of the hernia, with closure of the defect when it is possible.

This procedure can be done by laparoscopy or laparotomy, depending of the patients and the experience of the surgeon $[3,6]$.

Approximately $50 \%$ of the patients developed morbidity after surgical procedures. Age, delayed laparotomy time ( $>3$ days after the onset of the symptoms) and the presence of a comorbidity were related to morbidity $[10,11]$.

\section{Conclusion}

Primitive internal herniation remains a rare cause of consultation on emergency. It must be evocated in patients with no medical history and consulting for acute intestinal obstruction. CT scan suggests often the diagnosis that is confirmed at surgical exploration. The treatment is always surgery.

\section{References}

1. Armstrong O, Letessier E, Genier F, Lasserre P, Le Néel JC (1997) Internal hernia. Report of nine cases. Hernia 1: 143-145.

2. Ghiassi S, Nguyen SQ, Divino CM, Byrn JC, Schlager A (2007) Internal Hernias: Clinical Findings, Management, and Outcomes in 49 Nonbariatric Cases. J Gastrointest Surg 11: 291-295.

3. Narjis Y, Jgounni R, El Mansouri MN, Rabbani K, Hiroual R, et al. (2010) Transmesocolic internal herniation: a rare case of small bowel obstruction, "the Marrakesh hernia". Hernia 14: 427-429.

4. Meyers MA (1994) Dynamic radiology of the abdomen: normal and pathologic anatomy. (4th edn.) Springer-Verlag, New York, USA.

5. Akyildiz H, Artis T, Sozuer E, Akcan A, Kucuk C, et al. (2009) Internal hernia: Complex diagnostic and therapeutic problem. Inter J Surg 7: 334-337.

6. Gullino D, Giordano O, GuUino E (1993) internal hernias of the abdomen, about 14 cases. J Chir 130: 179 - 195

7. Martin LC, Merkle EM, Thompson WM (2006) Review of internal hernias: radiographic and clinical findings. Am J Roentgenol 186: 703-717.

8. Blachar A, Federle MP (2002) Internal hernia: an increasingly common cause of small bowel obstruction. Semin Ultrasound CT MR 23: 174-183.

9. Takeyama N, Gokan T, Ohgiya Y, Satoh S, Hashizume T, et al (2005) CT of internal hernias. Radiographics 25: 997-1015.

10. Fan HP, Yang AD, Chang JG, Juan CW, Wu HP (2008) Clinical spectrum of internal hernia: a surgical emergency. Surg Today 38: 899-904.

11. Newsom BD, Kukora JS (1986) Congenital and acquired internal hernias: unusual causes of small bowel obstruction. Am J Surg 152: 279-284. 